\title{
Induction of tissue-specific stem cells by reprogramming factors, and tissue-specific selection
}

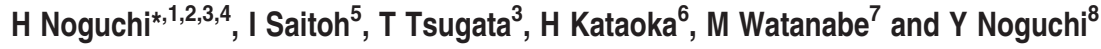

\begin{abstract}
Although induced pluripotent stem (iPS) cells have significant implications for overcoming most of the ethical issues associated with embryonic stem (ES) cells, there are still several unresolved issues related to the use of iPS cells for clinical applications, such as teratoma formation. In this study, we were able to generate tissue-specific stem (induced tissue-specific stem; iTS) cells from the pancreas (iTS-P) or liver (iTS-L) by transient overexpression of reprogramming factors, combined with tissue-specific selection. The generation of iTS cells was easier than that of iPS cells. The iTS-P/iTS-L cells express genetic markers of endoderm and pancreatic/hepatic progenitors and were able to differentiate into insulin-producing cells/hepatocytes more efficiently than ES cells. Subcutaneous transplantation of both types of iTS cells into immunodeficient mice resulted in no teratoma formation. The technology used for the transient overexpression of reprogramming factors and tissue-specific selection may be useful for the generation of other tissue-specific stem cells, and the generation of iTS cells could have important implications for the clinical application of stem cells.
\end{abstract}

Cell Death and Differentiation (2015) 22, 145-155; doi:10.1038/cdd.2014.132; published online 5 September 2014

Embryonic stem (ES) cells are capable of unlimited proliferation in vitro, while maintaining their potential to differentiate into cells from the three embryonic germ layers. Induced pluripotent stem (iPS) cells are generated from adult fibroblasts or other somatic cells, and are similar to ES cells in their morphology, gene expression, epigenetic status and in vitro differentiation. Mouse iPS cells give rise to adult chimeras and show competence for germline transmission. ${ }^{1-7}$ This technical breakthrough has significant implications for overcoming the ethical issues associated with ES cell derivation from embryos. The generation of mouse iPS cells without the genomic integration of exogenous reprogramming factors by the repeated transfection of plasmids expressing Oct3/4, Sox2 (sex-determining region Y-box2), KIf4 and $\mathrm{C}-\mathrm{Myc},{ }^{8}$ and by using nonintegrating adenoviruses transiently expressing the four factors ${ }^{9}$ has been reported. Moreover, the generation of human iPS cells without the genomic integration of exogenous reprogramming factors by plasmids expressing Oct3/4, Sox2, KIf4, C-Myc, Nanog, LIN28 and SV4OLT, ${ }^{10}$ or Oct3/4, Sox2, KIf4, L-Myc, LIN28 and p53 shRNA ${ }^{11}$ has been shown. These reports provide strong evidence that insertional mutagenesis is not required for in vitro reprogramming. The production of iPS cells without viral integration addresses a critical safety concern for the potential use of iPS cells in regenerative medicine. However, the use of iPS cells for clinical therapies is hampered by their potential for tumor formation and the limited ability to generate pure populations of differentiated cell types in vitro.

Adult tissue-specific stem/progenitor cells could represent one of the alternative sources for the treatment of diseases. Several in vitro studies have shown that insulin-producing cells (IPC) can be generated from adult pancreatic ductal tissues. $^{12-14}$ The assessment of 83 human islet grafts transplanted using the Edmonton Protocol since $1999^{15}$ showed that a significant positive correlation was observed between the number of islet progenitor (ductal-epithelial) cells transplanted and the long-term metabolic success, as assessed by an intravenous glucose tolerance test at $\sim 2$ years post-transplantation. Therefore, pancreatic duct/ progenitor cells could become a new source of IPC. One of the most difficult, and yet unresolved issues, is how to isolate pancreatic 'stem' cells, which have self-renewal capacity. We and other groups have established mouse pancreatic stem cell lines using specific culture conditions. ${ }^{16,17}$ One of our established pancreatic stem cell lines, HN\#13, derived from the pancreatic tissue of an 8-week-old mouse without genetic manipulation could be maintained during repeated passages for more than 1 year without growth inhibition under specific culture conditions. The HN\#13 cells do not have tumorigenic properties, and have normal chromosomes. The cells express

\footnotetext{
${ }^{1}$ Department of Surgery, Chiba-East National Hospital, National Hospital Organization, Chiba, Japan; ${ }^{2}$ Department of Regenerative Medicine, Graduate School of Medicine, University of the Ryukyus, Okinawa, Japan; ${ }^{3}$ Department of Gastroenterological Surgery, Okayama University Graduate School of Medicine, Dentistry and Pharmaceutical Sciences, Okayama, Japan; ${ }^{4}$ Natural and Environmental Sciences Program, The Open University of Japan, Chiba, Japan; ${ }^{5}$ Division of Pediatric Dentistry, Graduate School of Medical and Dental Science, Niigata University, Niigata, Japan; ${ }^{6}$ Department of Primary Care and Medical Education, Okayama University Graduate School of Medicine, Dentistry and Pharmaceutical Sciences, Okayama, Japan; ${ }^{7}$ Department of Urology, Okayama University Graduate School of Medicine, Dentistry and Pharmaceutical Sciences, Okayama, Japan and ${ }^{8}$ Department of Socio-environmental Design, Hiroshima International University, Hiroshima, Japan ${ }^{*}$ Corresponding author: H Noguchi, Department of Surgery, Chiba-East National Hospital, National Hospital Organization, 673 Nitona-cho, Chuo-ku, Chiba 260-8712, Japan. Tel: +81 43261 5171; Fax: +81 43268 2613; E-mail: n.hirofumi@ cehpnet.com or noguchih2006@yahoo.co.jp

Abbreviations: iPS, induced pluripotent stem; ES, embryonic stem; iTS, induced tissue-specific stem; iTS-P, iTS cells from the pancreas; iTS-L, iTS cells from the liver; Pdx1, the pancreatic and duodenal homeobox factor-1; iF, induced fibroblast-like; PCR, polymerase chain reaction; RT-PCR, reverse transcription PCR; Sox, sex-determining region Y-box; Hnf, hepatocyte nuclear factor; DE, definitive endoderm; GTE, gut tube endoderm; PP, pancreatic progenitors; IPC, insulin-producing cells; NeoR, neomycin resistance; $\alpha 1-A T, \alpha 1$-antitrypsin; G6PC, glucose 6-phosphatase; Pecam1, platelet/endothelial cell adhesion molecule 1; Mixl1, Mix1 homeobox-like 1; Zic1, zinc finger protein of the cerebellum 1; EP, endodermal progenitor; DMEM, Dulbecco's modified Eagle's medium; FBS, fetal bovine serum Received 04.2.14; revised 16.7.14; accepted 21.7.14; Edited by R De Maria; published online 5 September 2014
} 
the pancreatic and duodenal homeobox factor-1 (Pdx1), one of the transcription factors of the $\beta$-cell lineage. ${ }^{17}$ However, we were unable to isolate and culture mouse pancreatic stem cells from older donors ${ }^{18}$ or pancreatic stem cells from human pancreatic tissue. ${ }^{19}$ In the mouse study, pancreatic stem cells were isolated from the pancreata of all newborn mice examined. Meanwhile, pancreatic stem cells were isolated from only $10 \%$ of the pancreata of 8 -week-old mice, not from the pancreata of any 24 -week-old mice. ${ }^{18}$ These data suggest that young donors have a larger number of pancreatic stem cells, whereas that older donors have few or virtually no pancreatic stem cells. These data also indicate that it is extremely difficult to isolate pancreatic stem cells from older donors.

In this study, we were able to generate tissue-specific stem (induced tissue-specific stem; iTS) cells from mouse pancreatic tissue (iTS-P) by transient overexpression of reprogramming factors combined with $\mathrm{Pdx} 1$ selection. Furthermore, we were also able to generate iTS cells from the mouse liver (iTS-L) by transient overexpression of reprogramming factors combined with $\mathrm{HNF} 4 \alpha$ selection.

\section{Results}

Generation of iTS-P cells from mouse pancreatic tissue. We attempted to generate mouse iPS cells from older-donor pancreata by transfection of a single plasmid expressing Oct3/4, Sox2 and Klf4 with or without c-Myc. The three or four cDNAs were connected in this order with the $2 \mathrm{~A}$ peptide and inserted into a plasmid containing the $\mathrm{CMV}$ or $\mathrm{CAG}^{20}$ promoter (Supplementary Figure 1a). We transfected the OSKM plasmid (four factors) or OKS plasmid (three factors) into pancreatic tissue obtained from 24-week-old mice on days 1, 3, 5 and 7 (Figure 1a). We were able to generate only one colony of iPS cells from 24-week-old mouse pancreata using the OSKM plasmid during five experiments and were unable to generate iPS cells using the OKS plasmid throughout five experiments. However, we noticed that there were some cells that had self-renewing potential. The morphology of some cells was similar to that of mouse pancreatic stem cells, which we had previously established from young-donor pancreata without genetic manipulation. ${ }^{17}$ We designated them 'induced tissue-specific stem (iTS-P) cells'. Morphology of the other cells was similar to that of fibroblast cells, which we designated 'induced fibroblast-like (iF) cells' (Figure 1b).

To evaluate the plasmid integration in these cells (passage 45), genomic DNA was amplified by polymerase chain reaction (PCR) with specific primers (Supplementary Figure 1a; Supplementary Table 1). Although the PCR detected plasmid incorporation into the host genome of some cells, no amplification of plasmid DNA was observed in several cells, such as iTS-P 3F-1 and iTS-P 4F-1 (Supplementary Figures 1b and $\mathrm{c}$ ). Although we cannot formally exclude the presence of small plasmid fragments, these data show that some of the cells that have self-renewal capacity are most likely free from plasmid integration into the host genome.

Generative efficacy and characterization of iTS-P cells. To evaluate the efficiency of generating iTS-P cells, the OSKM plasmid or OKS plasmid were transfected into pancreatic tissue from five different mice that were 24 weeks old (one experiment using one mouse). A total of 14 colonies of iTS-P cells were generated using the OKS plasmid during five experiments, and a total of 41 colonies of ITS-P cells were generated using the OSKM plasmid during five experiments, thus suggesting that the OSKM plasmid induces iTS-P cells more efficiently than OKS plasmid. Moreover, the generation of iTS-P cells was easier than that of iPS cells (Figure 1c). Mock transfection (no factors) did not yield any iTS-P or iF cells. There was plasmid integration in two clones of the 14 colonies generated using the OKS plasmid (14.3\%) and in five clones of the 41 colonies generated using the OSKM plasmid $(12.2 \%)$.

To investigate the gene expression in these cells, a reverse transcription PCR (RT-PCR) analysis of ES cell marker genes was performed. The high-level expression of the pluripotency markers Oct3/4, Sox2 and Nanog was limited to ES and iPS cells (Supplementary Figure 2). We next investigated the gene expression patterns of endodermal/pancreatic progenitor (PP) cell markers. Differentiated cells from ES cells (generated by a stepwise differentiation protocol that relies on intermediates thought to be similar to the cell populations present in the developing embryo) ${ }^{21,22}$ were used as a positive control (Supplementary Figure 3a). The expression of marker genes of the definitive endoderm (DE; Sox17), gut tube endoderm (GTE; hepatocyte nuclear factor $4 \alpha$; Hnf $4 \alpha$ ) and PP (Pdx1) was detected in iTS-P cells, which was similar to the patterns detected in our mouse pancreatic stem cell line, HN\#13, but not iF, iPS or ES cells (Supplementary Figures $3 b-g)$.

The iTS-P 3F-1/4F-1 cells continued to divide actively beyond passage 80 without changes in their morphology or growth activity (Figure 1d). To examine the teratoma formation and tumorigenic potential in vivo, iTS-P 3F-1/4F-1 cells $\left(10^{6}-10^{7}\right.$ cells) at passage 45 were transplanted into nude or NOD/scid mice. No teratomas or tumors developed in the nude or NOD/scid mice that received iTS-P 3F-1/4F-1

Figure 1 Generation of iTS-P cells from mouse pancreatic tissue and differentiation of iTS-P cells into IPC. (a) Time schedules for the induction of iTS-P cells with the plasmid. Open arrowheads indicate the timing of cell seeding, passaging and colony pickup. Solid arrowheads indicate the timing of the transfections. (b) The morphology of mouse pancreatic tissue, HN\#13 cells, iTS-P 3F-1, iTS-P 4F-1, iF and iPS cells. Scale bars $=200 \mu$ m. (c) The colony numbers of iTS-P cells. The OSKM plasmid or OKS plasmid was transfected into pancreatic tissue from five different mice aged 24 weeks, and the number of colonies was counted after $30-45$ days. '1st, 2 nd,...' refers to the mouse number. (d) Growth curves of iTS-P cells (passage 45 and 80 ) and iF cells (passage 80). Error bars represent S.E. (e) Immunostaining of iTS-P 4F-1 cells (Pdx1) and IPC derived from iTS-P 4F-1 cells (insulin, C-peptide). Insulin staining of iF cells treated with the stepwise protocol was also performed. Scale bars $=50 \mu \mathrm{m}$. (f) The quantitative RT-PCR analysis of insulin genes in differentiated iTS-P 4F-1 cells. Differentiated cells derived from iTS-P 4F-1 cells (passage 45) by stage 4-5 and derived from ES cells by stage 1-5 were analyzed by quantitative RT-PCR. Isolated islets were used as positive control. The data are expressed as the insulin-to- $\beta$-actin ratio with that of the islets arbitrarily set at $100(n=4)$. Error bars represent S.E. (g) The insulin release assay. Differentiated iTS-P 4F-1 cells (passage 45) by the stage 4-5 protocol and derived from ES cells by the stage 1-5 protocol were stimulated with 2.8 and $20 \mathrm{mM} \mathrm{D-glucose,} \mathrm{and} \mathrm{the} \mathrm{amount} \mathrm{of} \mathrm{insulin} \mathrm{released} \mathrm{into} \mathrm{the} \mathrm{culture} \mathrm{supernatant} \mathrm{was} \mathrm{analyzed}$ by an ELISA. Error bars represent S.E. * $P<0.05$ 
cells during an observation period of at least 6 months, as is the case with HN\#13 cells. ${ }^{7}$ In contrast, the sites injected with $1 \times 10^{6}$ ES cells or iPS cells developed teratomas about 3 weeks after transplantation (Supplementary Figures 4a and b; Table 1). These data indicate that the iTS-P 3F/4F cells do not have the ability to form teratomas. a

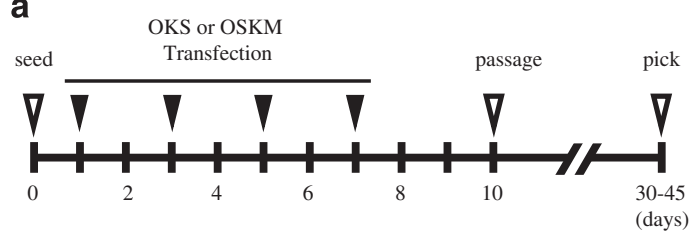

C

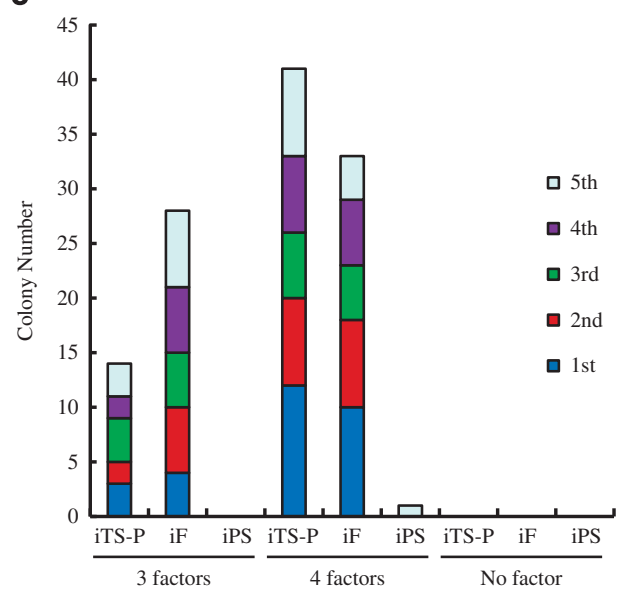

d

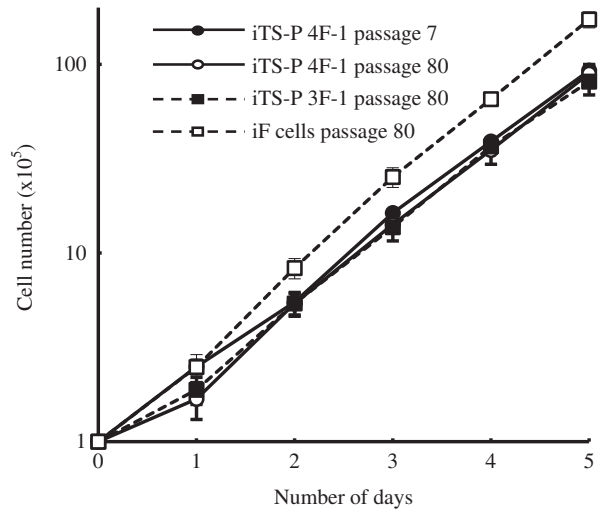

b
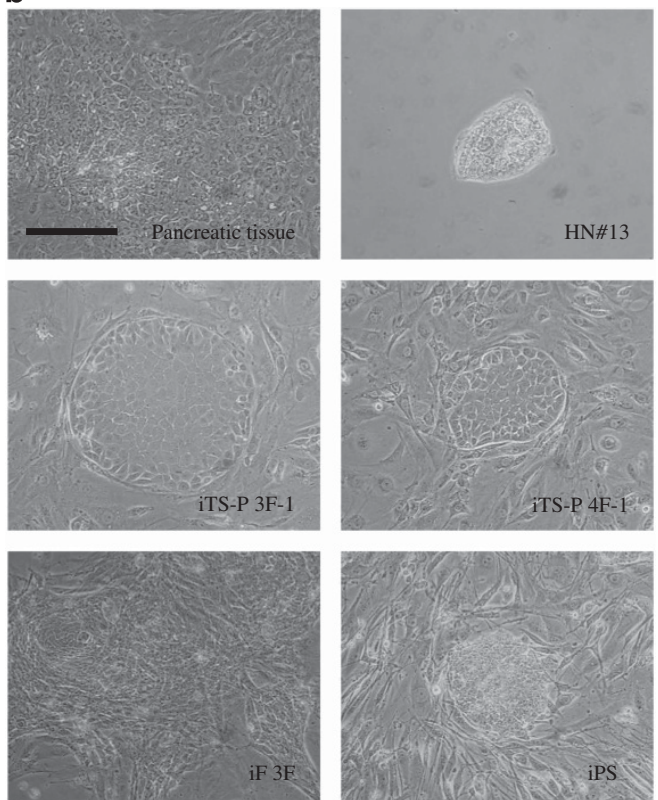

e

Insulin

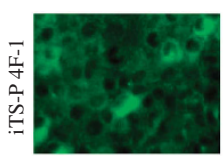

C-peptide

Insulin /

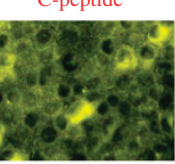

C-peptide / DAPI

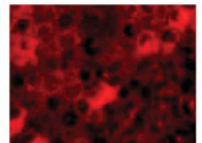

Insulin / DAPI
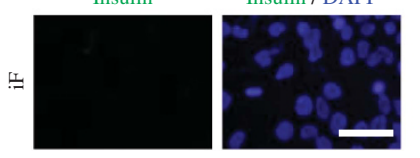

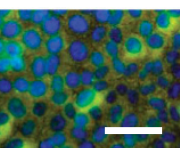

Pdx1 / DAPI

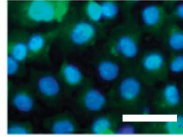

f

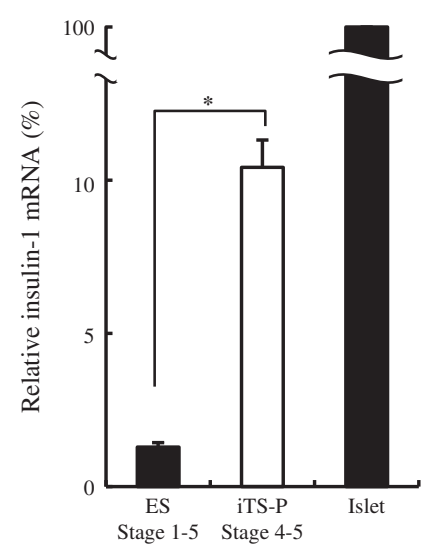

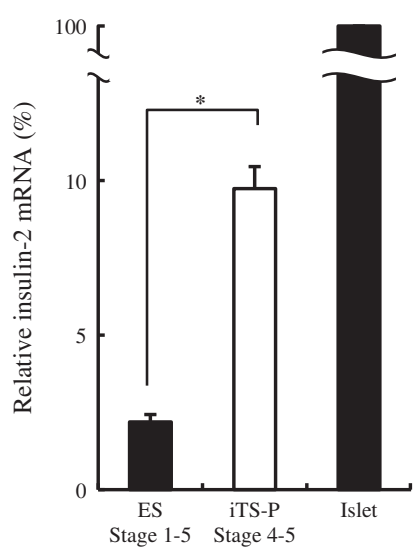

g

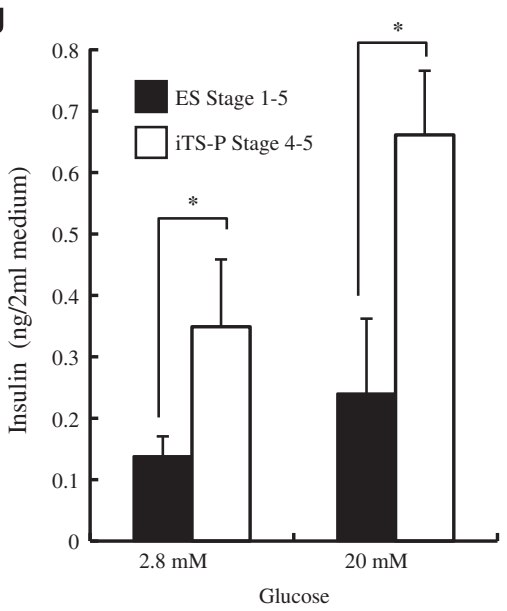


Differentiation of iTS-P cells into IPC. To determine whether iTS-P cells can be differentiated into IPC, we applied the stepwise differentiation protocol shown in Supplementary Figure $3 a$. The stepwise differentiation protocol relies on intermediates thought to be similar to cell populations present in the developing embryo. ${ }^{21,22}$ ES cells differentiate into DE in stage 1; the DE cells differentiate into GTE in stage 2; the GTE cells differentiate into PP in stage 3; and PP cells differentiate into IPC in stages 4 and 5. As iTS-P $4 \mathrm{~F}-1$ cells express endodermal cell markers (PP cell markers), we included stages 4 and 5 of the induction protocol in the stepwise differentiation protocol. Differentiated cells from ES cells (stage 1-5) were used as a control. The iTS-P 4F-1 cells were differentiated into IPC (Figure 1e; Supplementary Figure 4c) more efficiently than ES cells or iPS cells derived from pancreatic tissue by the stepwise differentiation protocol (Figure 1f; Supplementary Figure 4d). The insulin-positive cells were $\mathrm{C}$-peptide positive, thus excluding the possibility of insulin uptake from the media. $19.3 \pm 2.3 \%$ of the differentiated cells were insulin/C-peptide positive. The if cells were unable to be differentiated into IPC (Figure 1e). An RT-PCR analysis confirmed the expression

Table 1 Teratoma formation

\begin{tabular}{lclr}
\hline Cell type & $\begin{array}{c}\text { Injected } \\
\text { cell } \\
\text { number }\end{array}$ & $\begin{array}{l}\text { Mice bearing } \\
\text { teratoma/total mice } \\
\text { injected }\end{array}$ & $\begin{array}{r}\text { Period } \\
\text { (days) }\end{array}$ \\
\hline ES & $1 \times 10^{6}$ & $5 / 5$ (nude mice) & 60 \\
ES-derived $\beta$-cells & $1 \times 10^{6}$ & $2 / 5$ (nude mice) & 90 \\
iPS-P & $1 \times 10^{6}$ & $5 / 5$ (nude mice) & 60 \\
iTS-P 4F-1 & $1 \times 10^{6}$ & $0 / 5$ (nude mice) & 180 \\
iTS-P 4F-1 & $1 \times 10^{7}$ & $0 / 5$ (NOD/scid mice) & 180 \\
iTS-P 3F-1 & $1 \times 10^{6}$ & $0 / 5$ (nude mice) & 180 \\
iTS-P 4FP-1 & $1 \times 10^{7}$ & $0 / 5$ (NOD/scid mice) & 180 \\
iTS-P 4FP-2 & $1 \times 10^{7}$ & $0 / 5$ (NOD/scid mice) & 180 \\
iTS-P 4FP-4 & $1 \times 10^{7}$ & $0 / 5$ (NOD/scid mice) & 180 \\
iTS-P 4FP-6 & $1 \times 10^{7}$ & $0 / 5$ (NOD/scid mice) & 180 \\
iTS-P ${ }^{a}$-derived $\beta$-cells & $1 \times 10^{6}$ & $0 / 5$ (NOD/scid mice) & 180 \\
ES & $1 \times 10^{6}$ & $5 / 5$ (nude mice) & 60 \\
ES-derived hepatocytes & $1 \times 10^{6}$ & $3 / 5$ (nude mice) & 90 \\
iPS-L & $1 \times 10^{6}$ & $5 / 5$ (nude mice) & 60 \\
iTS-L 4F-1 & $1 \times 10^{7}$ & $0 / 5$ (nude mice) & 180 \\
iTS-L 4F-2 & $1 \times 10^{7}$ & $0 / 5$ (NOD/scid mice) & 180 \\
iTS-L ${ }^{\text {b }-d e r i v e d ~}$ & $1 \times 10^{6}$ & $0 / 5$ (NOD/scid mice) & 180 \\
hepatocytes & & & \\
& & &
\end{tabular}

Abbreviation: ES, embryonic stem

$a_{\text {iTS-P } 4 F P-1}$

biTS-L 4F-1 of endocrine-specific gene products, such as Glut2, glucokinase, NeuroD, Pax4, Nkx2.2, glucagon and somatostatin (Supplementary Figure 5a). To evaluate whether the differentiated cells had glucose sensitivity, the differentiated cells from the iTS-P 4F-1 clone were exposed to low $(2.8 \mathrm{mM})$ or high $(20 \mathrm{mM})$ concentrations of glucose. The cells released about sixfold higher amounts of mouse insulin than an ES-derived population at both glucose concentrations (Figure 1g). The stimulation index was similar between the differentiated cells from iTS-P 4F-1 cells and ES cells (Supplementary Figure 5b).

Generation of iTS-P cells by the expression plasmid and Pdx1 selection. We next attempted to achieve the efficient selection of iTS-P cells, as there was a large number of iF cells also included in the above experiments. As iTS-P 4F-1 cells expressed the Pdx1 transcription factor at both the mRNA (Supplementary Figure $3 g$ ) and protein level (Figure 1e), we used a plasmid containing a neomycin resistance (NeoR) gene that was driven by the $\mathrm{Pdx} 1$ promoter (Supplementary Figure 6a). We transfected the OSKM plasmid and pPdx1-NeoR plasmid together into the pancreatic tissue obtained from a 24-week-old mouse on days 1, 3, 5 and 7 (Figure 2a), and G418 was added to the ES culture media from day 10 to 15 to select Pdx1expressing cells. We obtained multiple colonies (iTS-P 4FP-1 to -6 ; Figure $2 \mathrm{~b}$ ) that had self-renewal capacity and were morphologically similar to iTS-P $4 \mathrm{~F}-1$ cells. There were no fibroblast-like colonies in this experiment. To evaluate the plasmid integration in these cells (passage 45), genomic DNA from these cells was amplified by PCR with the primers indicated in Supplementary Figure 1a. Although PCR detected plasmid incorporation into the host genome of some cells, no amplification of plasmid DNA was observed in iTS-P 4FP-1, -2 , -4 or -6 cells (Supplementary Figure 6b).

Generative efficacy and characterization of iTS-P 4FP cells. To evaluate the efficiency of generating iTS-P 4FP cells, the OSKM plasmid and pPdx1-NeoR plasmid were transfected into pancreatic tissue from five different mice that were 24 weeks old (one experiment using one mouse). A total of 20 colonies of iTS-P cells were generated using the OSKM plasmid and pPdx1-NeoR plasmid during five experiments (Figure 2c). As a total of 41 colonies of iTS-P 4F cells were generated using only the OSKM plasmid during five experiments, the efficiency of iTS-P cell generation

Figure 2 Generation of iTS-P 4FP cells by expression plasmid and Pdx1 selection. (a) Time schedules for the induction and selection of iTS-P cells with the plasmid. Open arrowheads indicate the timing of cell seeding, passaging and colony pickup. Solid arrowheads indicate the timing of transfection. Selection by neomycin was performed from day 10 to day 15. (b) The morphology of the iTS-P 4FP-1 to -6 cells. Scale bars $=200 \mu \mathrm{m}$. (c) The colony number of iTS-P 4FP cells. The OSKM plasmid and pPdx1-NeoR plasmid were transfected into pancreatic tissue from five different mice aged 24 weeks, and the number of colonies was counted after 30-45 days. '1st, 2nd,...' refers to the mouse number. (d) Quantitative RT-PCR analysis of ES cell marker genes in iTS-P 4FP cells. ES cells, pancreatic tissue and HN\#13 cells were used as controls. The data are expressed as the genes-to- $\beta$-actin ratio, with that of the differentiated cells arbitrarily set at 1 ( $n=4)$. E, ES cells; 1 , iTS-P 4FP-1 cells; 2 , iTS-P 4FP-2 cells; 4 , iTS-P 4FP-4 cells; 6, iTS-P 4FP-6 cells; P, pancreatic cells ( $90 \%>$ islets); H, HN\#13 cells. Error bars represent S.E. (e) Quantitative RT-PCR analysis of endodermal/pancreatic cell marker genes in iTS-P 4FP cells. ES cells, HN\#13 cells and cells differentiated from ES cells (DE, GTE and PP cells) were used as controls. The data are expressed as the genes-to$\beta$-actin ratio, with that of the differentiated cells arbitrarily set at $1(n=4)$. 1, iTS-P 4FP-1 cells; 2 , iTS-P 4FP-2 cells; 4 , iTS-P 4FP-4 cells; 6 , iTS-P 4FP-6 cells; H, HN\#13 cells; E, ES cells; D, DE cells; G, GTE cells; P, PP cells. Error bars represent S.E. ${ }^{*} P<0.05$ compared with ES cells. (f) The quantitative RT-PCR analysis of insulin genes in differentiated iTS-P 4FP cells. Differentiated cells derived from iTS-P 4FP-1, $-2,-4$ and -6 cells (passage 45) by the stage 4-5 protocol were analyzed by quantitative RT-PCR. Isolated islets were used as positive control. Data are expressed as the insulin-to- $\beta$-actin ratio, with that of the islets arbitrarily set at $100(n=4)$. Error bars represent S.E. (g) The results of the insulin release assay. Differentiated iTS-P 4FP-1, $-2,-4$ and -6 cells (passage 45) by the stage $4-5$ protocol were stimulated with 2.8 and $20 \mathrm{mM}$ D-glucose, and the amount of insulin released into the culture supernatant was analyzed by ELISA. Error bars represent S.E. 
decreased when the pPdx1-NeoR was also used. This may have been due to the relatively lower concentration of OSKM plasmid per cell due to the addition of pPdx1-NeoR. There was plasmid integration in three clones of the 20 colonies generated $(15.0 \%)$.
To investigate the gene expression profile in these cells, a RT-PCR analysis of ES cell marker genes, endodermal marker genes and pancreatic marker genes was performed (Figures 2d, e and 3). No teratomas or tumors developed in the NOD/scid mice receiving iTS-P 4FP-1, $-2,-4$ and -6 cells a

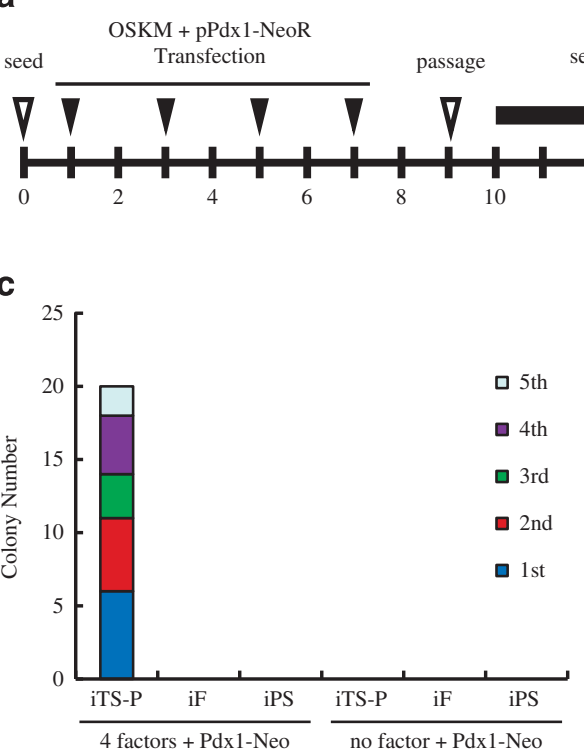

d

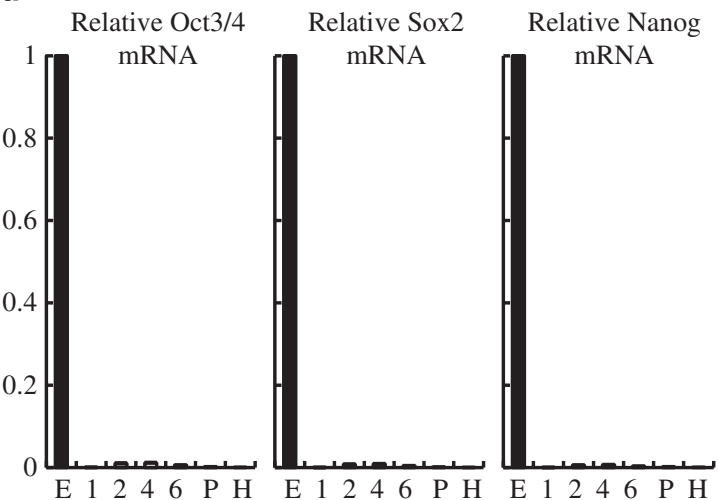

f
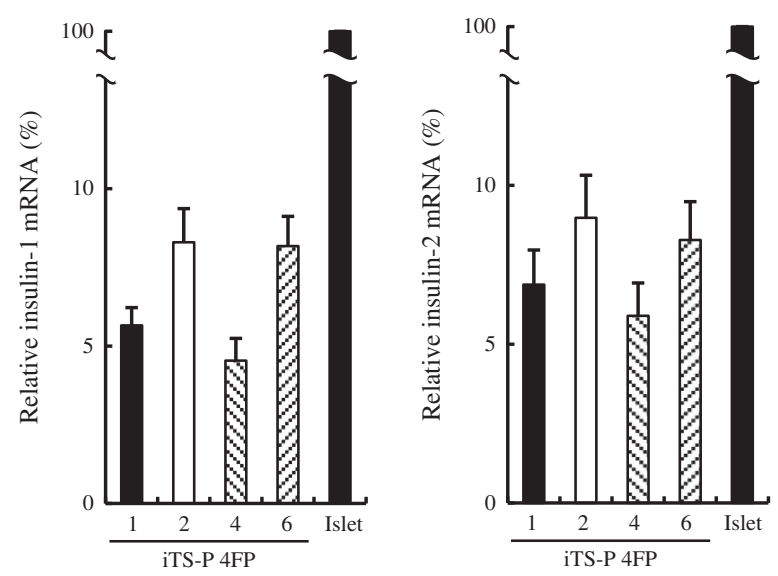

b
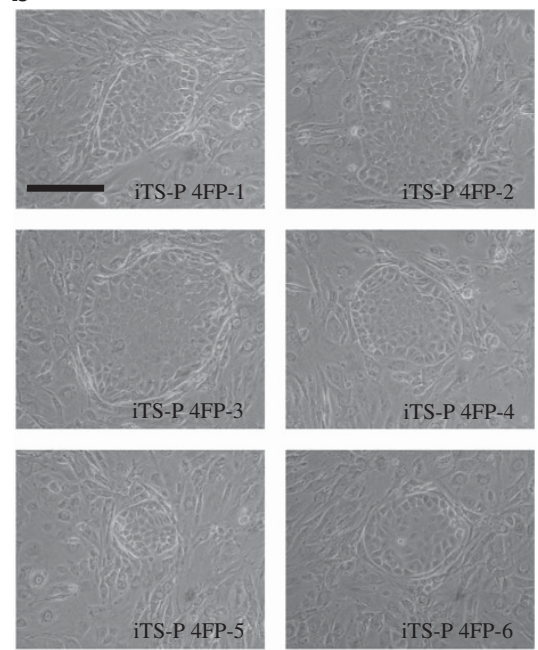

e

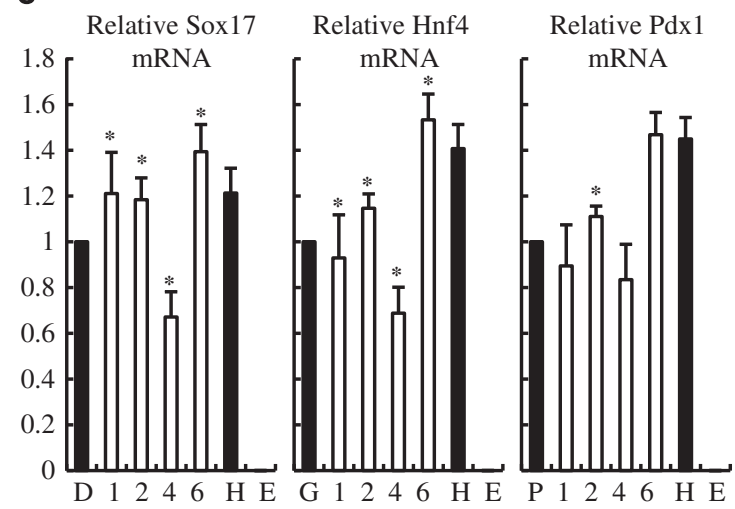

g

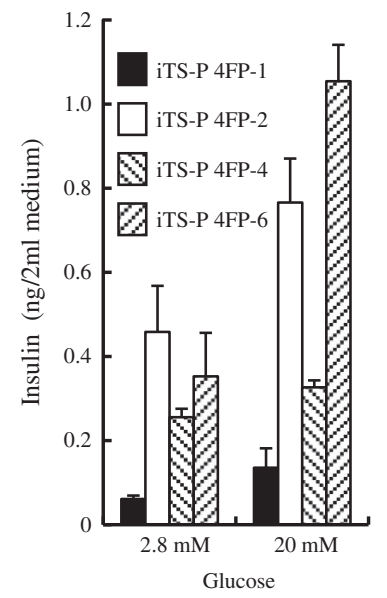


$\left(1 \times 10^{7}\right)$ at either stage during an observation period of at least 6 months (Table 1). These data indicate that the iTS-P 4FP cells express endodermal markers, and do not form teratomas.

Differentiation of iTS-P 4FP cells into IPC. To determine whether they could differentiate into IPC, we applied the stage 4-5 protocol from the stepwise differentiation protocol (shown in Supplementary Figure 3a) to the iTS-P 4FP cells. All of the iTS-P 4FP clones without plasmid integration were differentiated into IPC by the stage 4-5 protocol (Figure 2f;
Supplementary Figure 7 ). $20.0 \pm 1.4 \%$ of the differentiated cells were insulin/C-peptide positive on immunostaining and expressed endocrine-specific gene products (Supplementary Figure 8). All of the differentiated cells from iTS-P 4FP-1, -2, -4 and -6 cells released mouse insulin on exposure to both the low and high concentrations of glucose (Figure $2 \mathrm{~g}$ ), although the amount of insulin produced differed among the cells. The stimulation index was also different among the clones. These data suggest that the pPdx1-NeoR plasmid can efficiently select iTS-P cells, but the differentiation ability of the cells into IPC depends on the individual clone.
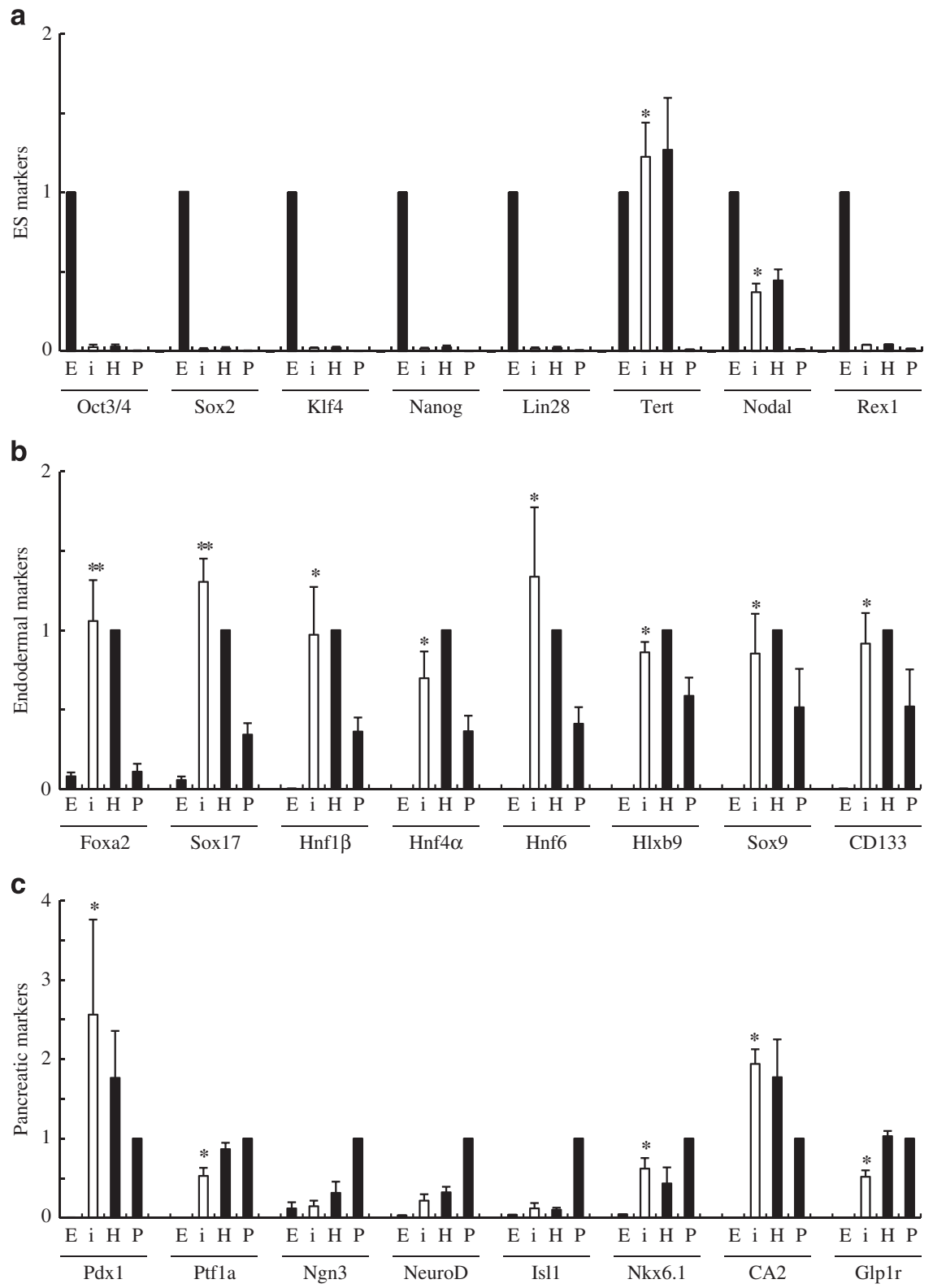

Figure 3 Quantitative RT-PCR analysis of ES and endodermal/pancreatic cell marker genes in iTS-P 4FP cells. (a) The quantitative RT-PCR analysis of ES cell marker genes in iTS-P 4FP cells. ES cells were used as control. ${ }^{*} P<0.05$ compared with pancreatic cells. (b) The quantitative RT-PCR analysis of endodermal cell marker genes in iTS-P 4FP cells. HN\#13 cells were used as control. ${ }^{*} P<0.05$ compared with ES cells. ${ }^{* *} P<0.05$ compared with ES cells or pancreatic cells. (c) The quantitative RT-PCR analysis of pancreatic cell marker genes in iTS-P 4FP cells. Pancreatic cells ( $90 \%>$ islets) were used as control. ${ }^{*} P<0.05$ compared with ES cells. E, ES cells; i, iTS-P 4FP-1 cells; H, HN\#13 cells; P, pancreatic cells $(90 \%>$ islets). The data are expressed as the genes-to- $\beta$-actin ratio, with that of the control cells arbitrarily set at 1 ( $n=4)$. The error bars represent S.E. 
Generation of iTS-L cells from mouse liver cells. We next attempted to generate iTS cells from mouse liver cells by transient overexpression of reprogramming factors, combined with HNF $4 \alpha$ selection. The OSKM plasmid was transfected into liver cells ( $>95 \%$ hepatocyte) from 24-weekold mice on days 1, 3, 5 and 7 (Figure 4a). We were able to generate four colonies of iPS cells during five experiments. The ITS-L cells were selected by a quantitative RT-PCR analysis of HNF4 $\alpha$ (Figure $4 \mathrm{~b}$ ). A total of 58 colonies of iTS-L cells were generated during five experiments (one experiment using one mouse), thus suggesting that the generation of iTS-L cells is easier than that of iPS cells (Figures 4c and $d$ ).

We evaluated the plasmid integration in these cells (passage 45). No amplification of plasmid DNA was observed in several cells, such as iTS-L 4F-1 (Supplementary Figure 9a). There was plasmid integration into seven clones of 58 colonies generated using the OSKM plasmid (12.1\%).

Characterization of iTS-L cells. To investigate the gene expression in these cells, an RT-PCR analysis of ES cell marker genes and endodermal marker genes was performed (Figure 4e; Supplementary Figures 9b, c and 10a). The iTS-L $4 \mathrm{~F}-1$ cells continued to divide actively beyond passage 80 without changes in their morphology or growth activity (Figure 4f). No teratomas or tumors developed in the nude mice that received iTS-L $4 \mathrm{~F}-1$ cells $\left(1 \times 10^{7}\right)$ at passage 45 during an observation period of at least 6 months. In contrast, sites injected with $1 \times 10^{6}$ ES cells developed teratomas about 3 weeks after transplantation (Supplementary Figure 10b; Table 1).

Differentiation of iTS-L cells into hepatocytes. To determine whether ITS-L cells can be differentiated into hepatocytes, we applied the differentiation protocol reported previously. ${ }^{23}$ The iTS-L cells were successfully differentiated into albumin-producing cells (Figure $4 \mathrm{~g}$ ). A quantitative RTPCR analysis confirmed the expression of hepatocytespecific gene products, such as $\alpha 1$-antitrypsin ( $\alpha 1-\mathrm{AT})$, glucose 6-phosphatase (G6PC) and albumin. The iTS-L 4F-1 cells were differentiated into hepatocytes more efficiently than ES cells or iPS cells derived from liver cells (Figures 5a and b; Supplementary Figure 10c). Other clones (iTS-L 4F-2 and iTS-L 4F-3) were also differentiated into hepatocyte (Supplementary Figure 10d), although the level of albumin mRNA differed among the cells. These data suggest that ITS-L cells can be differentiated into hepatocytes, but the differentiation ability depends on the individual clone.

Restriction of iTS cell developmental potential. To determine whether the developmental potential of iTS-P/ iTS-L cells was restricted to pancreas/liver lineages, respectively, cultures were induced using the conditions established to drive ES cells toward hepatocytes, IPC, neuroectoderm ${ }^{24}$ or mesoderm. ${ }^{23}$ The upregulation of albumin mRNA was limited to iTS-L cells (Figure $5 \mathrm{~b}$ ) and the upregulation of insulin mRNA was limited to iTS-P cells (Figure $5 \mathrm{c}$ ). Moreover, the upregulation of the mesoderm markers platelet/ endothelial cell adhesion molecule 1 (Pecam1) or Mix1 homeobox-like 1 (Mixl1; Figure 5d), and neuroectoderm markers zinc finger protein of the cerebellum 1 (Zic1) or Sox1 (Figure 5e), was not observed in either the iTS-P or iTS-L cells, thus suggesting that iTS cells are committed to a specific type of tissue development.

\section{Discussion}

The iPS technology has significant implications for overcoming most of the ethical issues associated with ES cell derivation from embryos. However, the iPS cells still have some ethical issues, because they have similar or the same potency as ES cells, such as issues posed by human cloning. When we focus on the treatment of patients, differentiated tissue is needed. Although islet/liver transplantation is an efficient strategy for the treatment of diabetes/liver failure, ${ }^{25}$ it is circumscribed by the limited and irregular supply of cadaveric donors and the risks of immunosuppressant therapy. In this study, we induced pancreatic/liver stem cells from mouse pancreatic tissue/liver cells by transient overexpression of reprogramming factors and tissue-specific selection. The iTS-P/iTS-L cells were able to differentiate into IPC/hepatocytes more efficiently than ES cells. On the other hand, the iTS-P/iTS-L cells did not differentiate into mesoderm or neuroectoderm. As the iTS-P/iTS-L cells are pancreas/liver-specific stem cells, the use of these cells seems to have fewer ethical concerns than ES cells and even iPS cells, because there are no concerns regarding their potential use to generate germ cells, and no need to destroy an embryo. Moreover, the iTS-P/iTS-L cells do not form teratomas. The ES/iPS cells have a risk for teratoma formation, even after transplantation of differentiated cells derived from ES/iPS cells, due to possible contamination with undifferentiated cells. This is one of the advantages of iTS-P/ iTS-L cells compared with ES/iPS cells in terms of their potential clinical use. On the other hand, we performed transplantation of undifferentiated iTS-P cells in normal nude mice and nude mice with diabetes; however, there were few/ no IPC in the grafts. We also performed transplantation of undifferentiated ITS-L cells in normal nude mice and nude mice with liver failure ( $90 \%$ hepatectomy); however, there were few/no albumin-producing cells in the grafts. These data suggest that undifferentiated iTS cells themselves cannot be used to treat the disease and that establishing differentiational protocols are important for clinical application.

Our control study using a plasmid with no factors showed no existing adult pancreatic stem cell population in the 24-weekold mice (Figure 1c). Therefore, iTS-P cells were definitively induced by three or four factors. It has recently been shown that, following the reprogramming of mouse/human iPS cells, an epigenetic memory is inherited from the parental cells. ${ }^{26-30}$ It was also shown that the epigenetic memory predisposes iPS cells derived from pancreatic $\beta$ cells to differentiate more readily into IPC. ${ }^{31}$ These findings demonstrate that the iPS cell phenotype may be influenced by their cells of origin, and suggest that their skewed differentiation potential may prove useful in the generation of differentiated cell types that are currently hard to produce from ES/iPS cells for the treatment of human diseases. The iTS-P/iTS-L cells have to be cells that inherit numerous components of epigenetic memory from 
a
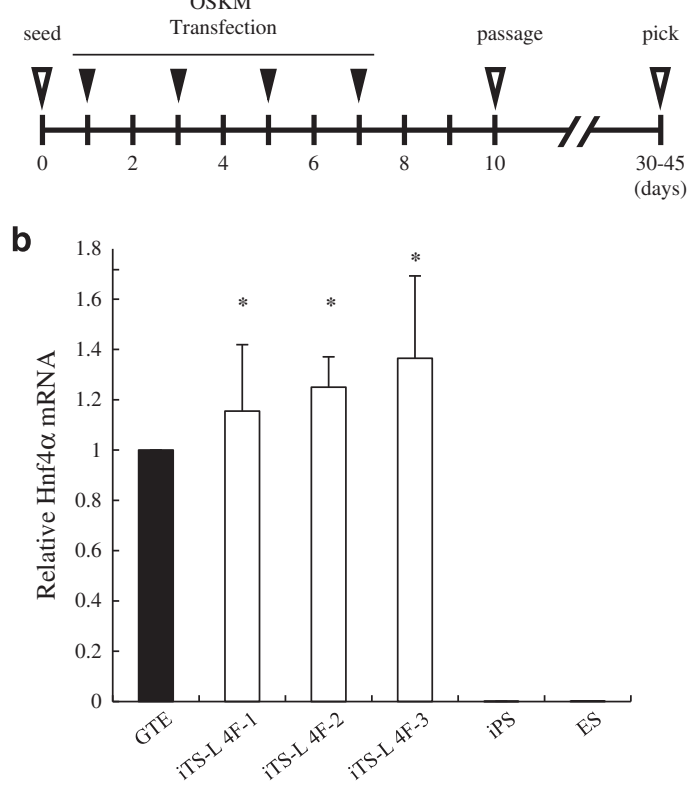

C
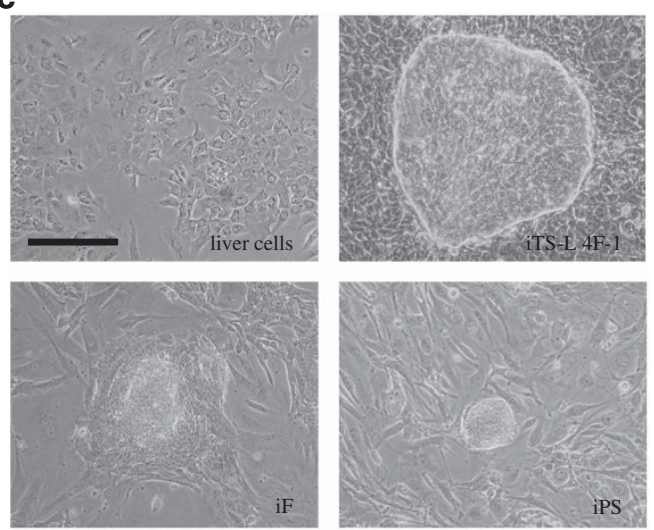

f

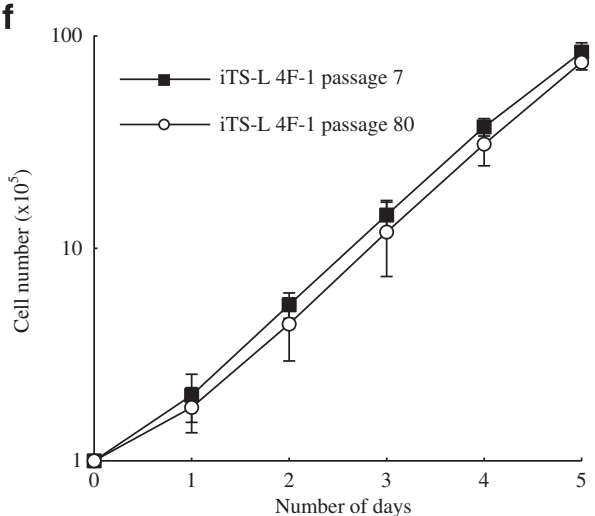

d

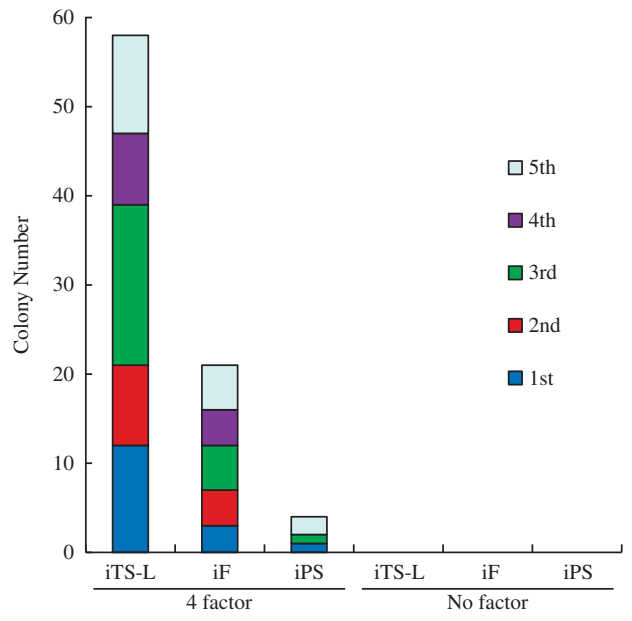

e
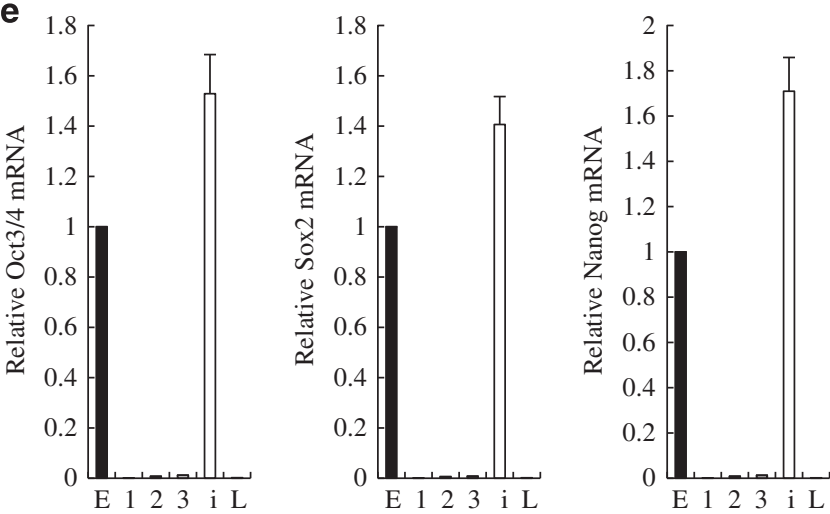

g
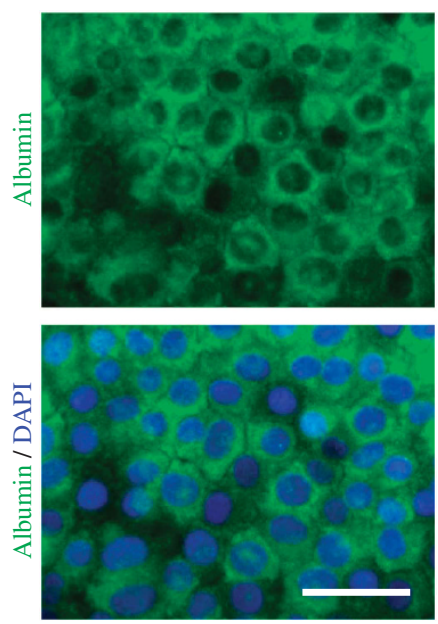

Figure 4 Generation of iTS-L cells by expression plasmid and Hnf $4 \alpha$ selection. (a) The time schedules for the induction of iTS-L cells with the plasmid. Open arrowheads indicate the timing of cell seeding, passaging and colony pickup. Solid arrowheads indicate the timing of transfection. (b) Selection of iTS-L cells by a quantitative RT-PCR analysis of the Hnf $4 \alpha$ gene in each colony. Each colony was analyzed by quantitative RT-PCR of the Hnf $4 \alpha$ gene. The GTE cells derived from ES cells were used as positive control, and iTS-L cells were defined as when the expression level of Hnf $4 \alpha$ gene was similar to that in GTE cells. The data are expressed as the Hnf $4 \alpha$ gene-to- $\beta$-actin ratio, with that of the GTE cells arbitrarily set at $1(n=4)$. Error bars represent S.E. ${ }^{*} P<0.05$ compared with iPS cells or ES cells. (c) The morphology of the liver cells, iTS-L, iF and iPS cells. Scale bars $=200 \mu \mathrm{m}$. (d) The colony number of iTS-L cells. The OSKM plasmid was transfected into liver cells from five different mice aged 24 weeks, and the number of colonies was counted after 30-45 days. '1st, 2nd,...' refers to the mouse number. (e) The quantitative RT-PCR analysis of the Oct3/4, Sox2 and Nang gene expression in iTS-L 4F cells. ES cells and liver cells ( > 95\% hepatocyte) were used as controls. The data are expressed as the genes-to- $\beta$-actin ratio, with that of the ES cells arbitrarily set at $1(n=4)$. E, ES cells; 1 , iTS-L 4F-1 cells; 2, iTS-L 4F-2 cells; 3, iTS-L 4F-3 cells; i, iPS cells; L, liver cells. Error bars represent S.E. (f) Growth curves of iTS-L cells (passage 7 and 80). Error bars represent S.E. (g) Immunostaining of albumin-producing cells derived from iTS-L 4F-1 cells. Scale bars $=50 \mu \mathrm{m}$ 
a
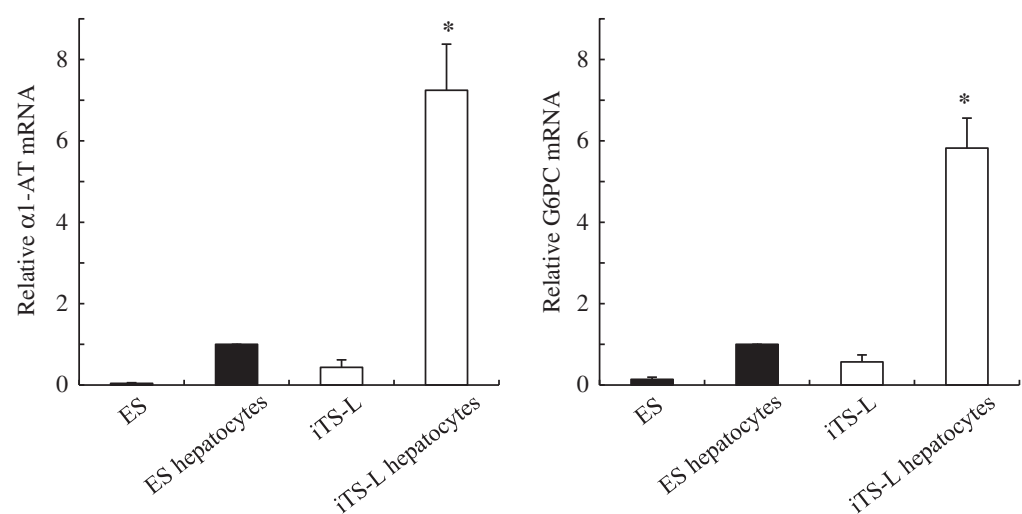

b

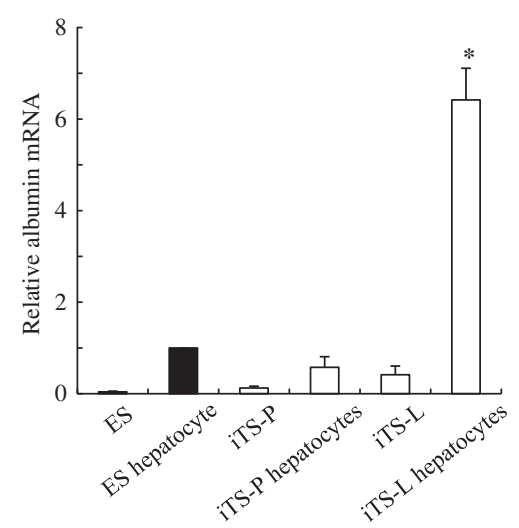

d
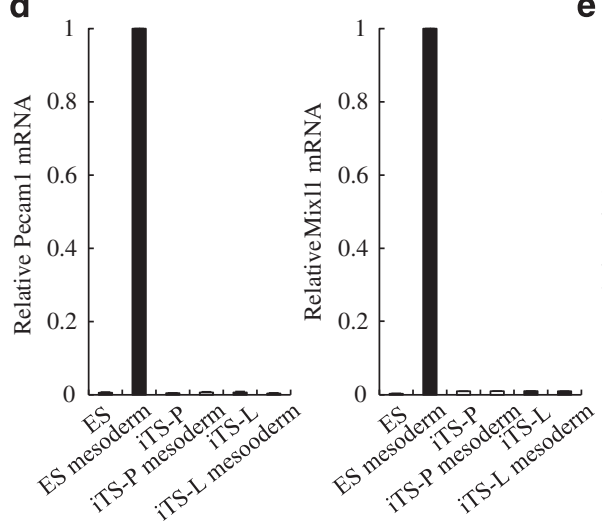

C
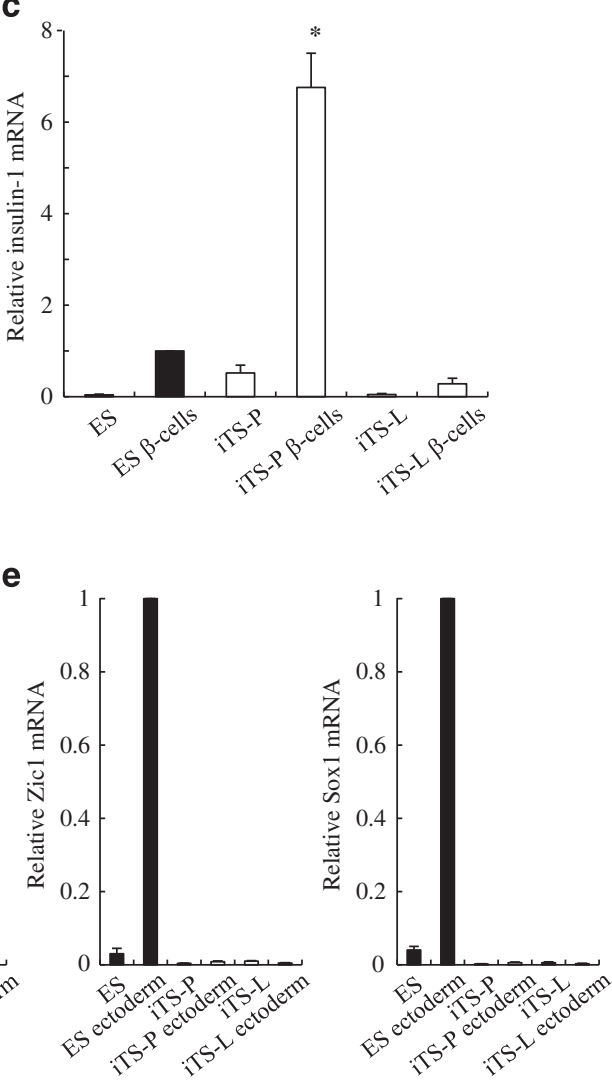

Figure 5 Differentiation of iTS-L cells into hepatocytes and restriction of iTS cell developmental potential. (a) The quantitative RT-PCR analysis of the $\alpha 1-A T$ and G6PC genes in differentiated iTS-L cells. Differentiated cells derived from iTS-L 4F-1 cells (passage 45) were analyzed by quantitative RT-PCR. ${ }^{*} P<0.05$ compared with iTS-L cells or ES cells. (b) The quantitative RT-PCR analysis of the albumin gene in differentiated or undifferentiated iTS-P/iTS-L cells. * $P<0.05$ compared with other cells. (c) The quantitative RT-PCR analysis of the insulin-1 gene in differentiated or undifferentiated iTS-P/iTS-L cells. ${ }^{*} P<0.05$ compared with other cells. (d) The quantitative RT-PCR analysis of mesodermal genes (Pecam1 and Mixl1) in differentiated or undifferentiated iTS-P/iTS-L cells. (e) The quantitative RT-PCR analysis of neuroectodermal genes (Zic1 and Sox1) in differentiated or undifferentiated iTS-P/iTS-L cells. iTS-P 4F-1 and iTS-L 4F-1 cells and the differentiated cells derived from iTS-P 4F-1 and iTS-L 4F-1 cells (passage 45) were analyzed by quantitative RT-PCR. ES cells and the differentiated cells derived from ES cells were used as controls. The data are expressed as the genesto- $\beta$-actin ratio, with that of the differentiated cells from ES cells arbitrarily set at $1(n=4)$. Error bars represent S.E.

pancreas/liver cells and that acquire self-renewal potential. Cheng et al. recently reported self-renewing endodermal progenitor (EP) cell lines derived from human ES/iPS cells. Their EP cells differentiated into numerous endodermal lineages, including pancreatic $\beta$ cells, hepatocytes and intestinal epithelia, but not ectodermal/mesodermal lineages. Moreover, the EP cells were non-tumorigenic in vivo. ${ }^{23}$ These findings also support the generation of iTS-P/iTS-L cells, which are non-tumorigenic in vivo.

Some groups have shown that overexpression of Pdx1, Ngn3, NeuroD and/or MafA by adenoviruses in vivo directly converted liver cells s2-34 $^{32}$ pancreatic tissue ${ }^{35}$ into IPC, suggesting that direct reprogramming without reversion to a pluripotent stem cell state is possible. These reports of direct 
reprogramming without reversion to a pluripotent stem cell state seem to have fewer related ethical issues than iPS cells. However, these strategies require a large number of mature cells, and the induction therapy has to be done on all of these cells directly, because they are not stem cells and do not have self-renewal capacity. Two major advantages of iPS/iTS cells are that they can be generated from a small number of cells, and they will expand to a sufficient number of cells because they have self-renewal capacity.

In this study, we used crude material instead of defined pancreatic populations. Our recent study showed that iTS-P cells can be generated from both islet and non-islet cell populations. Moreover, we recently established iTS-P cells using the pancreatic tissue of NOD mice, suggesting that iTS-P cells can be generated from pancreatic cells derived from patients with type 1 diabetes.

In conclusion, we generated iTS cells from mouse pancreas/liver cells by transient overexpression of reprogramming factors and tissue-specific selection. The generation of iTS-P/iTS-L cells and their differentiation into IPC/ hepatocytes have important implications due to their potential use for autologous cell replacement therapy, and because they appear to be more easily and efficiently differentiated than ES cells. The technology to generate iTS cells by reprogramming factors and tissue-specific selection may also be useful for the generation of other tissue-specific stem cells.

\section{Materials and Methods}

Mice and cell culture. All mouse studies were approved by the review committee of Okayama University Graduate School of Medicine, Dentistry and Pharmaceutical Sciences and Chiba-East National Hospital, National Hospital Organization. The 24-week-old C57/BL6 mice (CREA) were used for primary pancreatic/liver tissue preparations. Each mouse pancreas/liver was digested with $2 \mathrm{ml}$ cold M199 medium containing $2 \mathrm{mg} / \mathrm{ml}$ collagenase (Roche Diagnostics Corporation, Indianapolis, IN, USA). The digested tissues were cultured in Dulbecco's modified Eagle's medium (DMEM; Life Technologies, Carlsbad, CA, USA) with $10-20 \%$ fetal bovine serum (FBS; BIO-WEST, Inc., Logan, UT, USA). The 8-week-old nude or NOD/scid mice (CREA) were used for teratoma formation studies.

Mouse ES cells (ATCC, Manassas, VA, USA), iPS cells and iTS cells were maintained in complete ES cell media w/15\% FBS (Millipore, Billerica, MA, USA) on feeder layers of mitomycin C-treated STO or SNB cells, as described previously. ${ }^{1,36}$ ES cells were passaged every 3 days, and iTS cells were passaged every 5 days.

Plasmid construction and transfection. To generate the OSKM plasmid, the cDNAs encoding Oct3/4, Sox2, Klf4 and c-Myc were connected in this order with the $2 \mathrm{~A}$ peptide and inserted into a plasmid containing the CMV promoter. The OKS (Addgene, Cambridge, MA, USA: Plasmid 19771 (pCX-OKS2A)) or OSKM plasmid was transfected into pancreas/liver cells from 24-week-old mice on days $1,3,5$ and 7 , as previously described. ${ }^{8}$ Colonies were manually picked at 30-45 days after first transfection. To attempt efficient selection of iTS-P cells, we used a plasmid containing a NeoR gene that was driven by the $\mathrm{Pdx} 1$ promoter (pPdx1). To generate the $\mathrm{pPdx} 1-\mathrm{NeoR}$ plasmid, the Cre gene in the Pdx1-Cre plasmid (Addgene: Plasmid 15021 (DM\#258); https://www.addgene.org/ 15021/) was replaced with the NeoR gene, derived from pIRES-neo (Clontech, Mountain View, CA, USA). The detail protocol is shown in Supplementary Information.

DNA purification and PCR. DNA was extracted from cells using the AllPrep DNA/RNA Mini Kit (Qiagen, Tokyo, Japan). Polymerization reactions were performed in a Perkin-Elmer 9700 Thermocycler with $3 \mu \mathrm{l}$ cDNA (20 ng DNA equivalents), $160 \mu \mathrm{mol} / /$ cold dNTPs, $10 \mathrm{pmol}$ appropriate oligonucleotide primers, $1.5 \mathrm{mmol} / / \mathrm{MgCl}_{2}$ and $5 \mathrm{U}$ AmpliTaq Gold DNA polymerase (Perkin-Elmer, Norwalk, CT, USA) in $1 \times$ PCR buffer. The oligonucleotide primers are shown in Supplementary Table 1. The thermal cycle profile used a 10-min denaturing step at
$94{ }^{\circ} \mathrm{C}$, followed by amplification cycles $\left(1 \mathrm{~min}\right.$ denaturation at $94^{\circ} \mathrm{C}, 1$ min annealing at $57-62^{\circ} \mathrm{C}$ and $1 \mathrm{~min}$ extension at $72^{\circ} \mathrm{C}$ ) with a final extension step of $10 \mathrm{~min}$ at $72{ }^{\circ} \mathrm{C}$.

RT-PCR/quantitative PCR. Total RNA was extracted from cells using the AllPrep DNA/RNA Mini Kit or RNeasy Mini Kit (Qiagen). After quantifying the RNA by spectrophotometry, $2.5 \mu \mathrm{g}$ of RNA was heated at $85^{\circ} \mathrm{C}$ for $3 \mathrm{~min}$ and then reverse transcribed into CDNA in a $25-\mu$ l solution containing $200 \mathrm{U}$ of Superscript II RNase H-RT (Life Technologies), $50 \mathrm{ng}$ random hexamers (Life Technologies), $160 \mu \mathrm{mol} / \mathrm{I} \mathrm{dNTP}$ and $10 \mathrm{nmol} / \mathrm{l}$ dithiothreitol. The reaction consisted of $10 \mathrm{~min}$ at $25^{\circ} \mathrm{C}, 60 \mathrm{~min}$ at $42^{\circ} \mathrm{C}$ and $10 \mathrm{~min}$ at $95^{\circ} \mathrm{C}$. Polymerization reactions were performed as shown in the DNA purification and PCR section. The oligonucleotide primers are shown in Supplementary Table 1.

Quantification of the mRNA levels was carried out using the TagMan real-time PCR system, according to the manufacturer's instructions (Applied Biosystems, Foster City, CA, USA). PCR was performed for 40 cycles, including 2 min at $50^{\circ} \mathrm{C}$ and $10 \mathrm{~min}$ at $95^{\circ} \mathrm{C}$ as initial steps. In each cycle, denaturation was performed for $15 \mathrm{~s}$ at $95^{\circ} \mathrm{C}$ and annealing/extension was performed for $1 \mathrm{~min}$ at $60^{\circ} \mathrm{C}$. PCR was carried out in $20 \mu$ l of solution using cDNAs synthesized from $1.11 \mathrm{ng}$ of total RNA. For each sample, the expression of mRNA was normalized by dividing the $\beta$-actin expression level. Primers for mouse insulin-1, insulin-2, $\alpha 1-A T$, G6PC, albumin, Pecam1, Mixl1, Zic1, Sox1, Oct3/4, Sox2, Nanog, Sox17, Hnf4 $\alpha$, Pdx1 and $\beta$-actin are commercially available (Assays-on-Demand Gene Expression Products; Applied Biosystems).

Cell induction and differentiation. Directed differentiation into IPC was conducted as described previously, ${ }^{21,22}$ with minor modifications. ES cells, iPS cells (passage 45), iTS-P cells (passage 45 and 80 ) were used in this experiment. In stage 1, cells were treated with $25 \mathrm{ng} / \mathrm{ml}$ of Wnt3a and $100 \mathrm{ng} / \mathrm{ml}$ of activin A (R\&D Systems, Minneapolis, MN, USA) in RPMI (Life Technologies) for 1 day, followed by treatment with $100 \mathrm{ng} / \mathrm{ml}$ of activin A in RPMI $+0.2 \%$ FBS for 2 days. In stage 2, the cells were treated with $50 \mathrm{ng} / \mathrm{ml}$ of FGF10 (R\&D Systems) and $0.25 \mu \mathrm{M}$ of KAAD-cyclopamine (Toronto Research Chemicals, Toronto, ON, Canada) in $\mathrm{RPMI}+2 \% \mathrm{FBS}$ for 3 days. In stage 3 , the cells were treated with $50 \mathrm{ng} / \mathrm{ml}$ of FGF10, $0.25 \mu \mathrm{M}$ of KAAD-cyclopamine and $2 \mu \mathrm{M}$ of all-trans retinoic acid (Sigma-Aldrich, St. Louis, MO, USA) in DMEM + 1\% (vol/vol) B27 supplement (Life Technologies) for 3 days. In stage 4 , the cells were treated with $1 \mu \mathrm{M}$ of DAPT (Sigma-Aldrich) and $50 \mathrm{ng} / \mathrm{ml}$ of exendin-4 (Sigma-Aldrich) in DMEM $+1 \%$ (vol/vol) B27 supplement for 3 days. In stage 5 , the cells were then treated with $50 \mathrm{ng} / \mathrm{ml}$ of exendin-4, $50 \mathrm{ng} / \mathrm{ml}$ of IGF-1 (Sigma-Aldrich) and $50 \mathrm{ng} / \mathrm{ml}$ of HGF (R\&D Systems) in CMRL (Life Technologies) +1\% (vol/vol) B27 supplement for 3-6 days. Differentiation into hepatocytes, neuroectoderm or mesoderm was conducted as reported previously. ${ }^{23,24}$

Teratoma formation/tumorigenicity assay. A total of $1 \times 10^{6}-1 \times 10^{7}$ of IPS/iTS cells were inoculated into one thigh each of nude or NOD/scid mice. As a positive control, we transplanted $1 \times 10^{6} \mathrm{ES}$ cells or iPS cells into the other thigh of the nude or NOD/scid mice.

Immunostaining. Cells were fixed with $4 \%$ paraformaldehyde in PBS buffer. After blocking with $20 \%$ AquaBlock (EastCoast Bio, North Berwick, ME, USA) for $30 \mathrm{~min}$ at room temperature, the cells were incubated overnight at $4{ }^{\circ} \mathrm{C}$ with a goat anti-insulin antibody (1:100; Abcam, Tokyo, Japan), rabbit anti-C-peptide antibody (1:100; Cell Signaling Technology, Danvers, MA, USA), rabbit anti-Pdx1 antiserum ${ }^{37}$ (1:1000) or rabbit anti-albumin (Cedarline, Gymea, NSW, Australia) and then for $1 \mathrm{~h}$ at room temperature with FITC-conjugated anti-goat IgG (1:250; Abcam), Alexa Fluor 647-conjugated anti-rabbit IgG (1:250; Cell Signaling Technology) or FITC-conjugated anti-rabbit IgG (1:100; Jackson Immunochemicals, West Grove, PA, USA). Mounting medium for fluorescence with DAPI (Vector Laboratories, Peterborough, UK) was used for mounting. Percentage of insulin/C-peptide-positive cells was calculated by ratio of immunostaining positive cells/DAPI-positive cells in 10 visual fields.

Insulin release assay. The insulin release was measured by incubating the cells in Functionality/Viability Medium CMRL1066 (Mediatech, Inc., Manassas, VA, USA). The cells were washed three times in PBS and incubated in the solution (Functionality/Viability Medium CMRL1066) with $2.8 \mathrm{mM}$ D-glucose six times for $20 \mathrm{~min}$ (total $2 \mathrm{~h}$ ) each to wash them. The cells were then incubated in the solution with $2.8 \mathrm{mM} \mathrm{D}$-glucose for $2 \mathrm{~h}$, and then in the solution with $20 \mathrm{mM} \mathrm{D}$-glucose for 
$2 \mathrm{~h}$. The insulin levels in the culture supernatants were measured using an Ultra Sensitive Mouse Insulin ELISA (enzyme-linked immunosorbent assay) kit (Mercodia, Uppsala, Sweden). The stimulation index was calculated by dividing the insulin values measured from the $20 \mathrm{mM}$ glucose samples by $2.8 \mathrm{mM}$ glucose samples.

Statistical analyses. The data are expressed as the means \pm S.E. Two groups were compared using Student's $t$-test. The differences between each group were considered to be significant if the $P$-value was $<0.05$.

\section{Conflict of Interest}

The authors declare no conflict of interest.

Acknowledgements. This work was supported in part by the Japan Society for the Promotion of Science and the Ministry of Health, Labour and Welfare.

\section{Author contributions}

$\mathrm{HN}$ designed the experiments and analyzed the data. $\mathrm{HN}$ carried out most of the experimental work with the help of IS and TT. HK, MW and YN provided materials and discussion. HN wrote the manuscript. All authors discussed and commented on the manuscript.

1. Takahashi K, Yamanaka S. Induction of pluripotent stem cells from mouse embryonic and adult fibroblast cultures by defined factors. Cell 2006; 126: 663-676.

2. Takahashi K, Tanabe K, Ohnuki M, Narita M, Ichisaka T, Tomoda K et al. Induction of pluripotent stem cells from adult human fibroblasts by defined factors. Cell 2007; 131: 861-872.

3. Yu J, Vodyanik MA, Smuga-Otto K, Antosiewicz-Bourget J, Frane JL, Tian S et al. Induced pluripotent stem cell lines derived from human somatic cells. Science 2007; 318: 1917-1920.

4. Park IH, Zhao R, West JA, Yabuuchi A, Huo H, Ince TA et al. Reprogramming of human somatic cells to pluripotency with defined factors. Nature 2008; 451: 141-146.

5. Maherali N, Sridharan R, Xie W, Utikal J, Eminli S, Arnold K et al. Directly reprogrammed fibroblasts show global epigenetic remodeling and widespread tissue contribution Cell Stem Cell 2007; 1: 55-70.

6. Okita K, Ichisaka T, Yamanaka S. Generation of germline-competent induced pluripotent stem cells. Nature 2007; 448: 313-317.

7. Wernig $M$, Meissner A, Foreman R, Brambrink $T$, Ku M, Hochedlinger $K$ et al In vitro reprogramming of fibroblasts into a pluripotent ES-cell-like state. Nature 2007; 448 318-324.

8. Okita K, Nakagawa M, Hyenjong H, Ichisaka T, Yamanaka S. Generation of mouse induced pluripotent stem cells without viral vectors. Science 2008; 322: 949-953.

9. Stadtfeld M, Nagaya M, Utikal J, Weir G. Hochedlinger K. Induced pluripotent stem cells generated without viral integration. Science 2008; 322: 945-949.

10. Yu J, Hu K, Smuga-Otto K, Tian S, Stewart R, Slukvin II et al. Human induced pluripotent stem cells free of vector and transgene sequences. Science 2009; 324: 797-801.

11. Okita $K$, Matsumura $Y$, Sato $Y$, Okada A, Morizane A, Okamoto $S$ et al. A more efficient method to generate integration-free human iPS cells. Nat Methods 2011; 8: 409-412.

12. Bonner-Weir S, Taneja M, Weir GC, Tatarkiewicz K, Song KH, Sharma A et al. In vitro cultivation of human islets from expanded ductal tissue. Proc Natl Acad Sci USA 2000; 97 7999-8004.

13. Heremans Y, Van De Casteele M, in't Veld P, Gradwohl G, Serup P, Madsen $O$ et al. Recapitulation of embryonic neuroendocrine differentiation in adult human pancreatic duct cells expressing neurogenin 3. J Cell Biol 2002; 159: 303-312.

14. Gao R, Ustinov J, Pulkkinen MA, Lundin K, Korsgren O, Otonkoski T. Characterization of endocrine progenitor cells and critical factors for their differentiation in human adult pancreatic cell culture. Diabetes 2003; 52: 2007-2015.
15. Street CN, Lakey JR, Shapiro AM, Imes S, Rajotte RV, Ryan EA et al. Islet graft assessment in the Edmonton Protocol: implications for predicting long-term clinical outcome. Diabetes 2004; 53: 3107-3114.

16. Yamamoto T, Yamato E, Taniguchi H, Shimoda M, Tashiro F, Hosoi M et al. Stimulation of cAMP signalling allows isolation of clonal pancreatic precursor cells from adult mouse pancreas. Diabetologia 2006; 49: 2359-2367.

17. Noguchi H, Oishi K, Ueda M, Yukawa H, Hayashi S, Kobayashi $\mathrm{N}$ et al. Establishment of mouse pancreatic stem cell line. Cell Transplant 2009; 18: 563-571.

18. Kuise T, Noguchi H, Saitoh I, Kataoka HU, Watanabe M, Fujiwara T. Isolation efficiency of mouse pancreatic stem cells is age-dependent. Cell Med 2013; 5 : 69-73.

19. Noguchi H, Naziruddin B, Jackson A, Shimoda M, Ikemoto T, Fujita $Y$ et al. Characterization of human pancreatic progenitor cells. Cell Transplant 2010; 19: 879-886.

20. Niwa H, Yamamura K, Miyazaki J.. Efficient selection for high-expression transfectants with a novel eukaryotic vector. Gene 1991; 108: 193-199.

21. D'Amour KA, Bang AG, Eliazer S, Kelly OG, Agulnick AD, Smart NG et al. Production of pancreatic hormone-expressing endocrine cells from human embryonic stem cells. Nat Biotechnol 2006; 24: 1392-1401.

22. Kroon E, Martinson LA, Kadoya K, Bang AG, Kelly OG, Eliazer S et al. Pancreatic endoderm derived from human embryonic stem cells generates glucose-responsive insulin-secreting cells in vivo. Nat Biotechnol 2008; 26: 443-452.

23. Cheng X, Ying L, Lu L, Galvão AM, Mills JA, Lin $H C$ et al. Self-renewing endodermal progenitor lines generated from human pluripotent stem cells. Cell Stem Cell 2012; 10: 371-384.

24. Greber B, Coulon P, Zhang M, Moritz S, Frank S, Müller-Molina AJ et al. FGF signalling inhibits neural induction in human embryonic stem cells. EMBO J 2011; 30: 4874-4884.

25. Shapiro AM, Lakey JR, Ryan EA, Korbutt GS, Toth E, Warnock GL et al. Islet transplantation in seven patients with type 1 diabetes mellitus using a glucocorticoid-free immunosuppressive regimen. N Engl J Med 2000; 343: 230-238.

26. Kim K, Doi A, Wen B, Ng K, Zhao R, Cahan $\mathrm{P}$ et al. Epigenetic memory in induced pluripotent stem cells. Nature 2010; 467: 285-290.

27. Polo JM, Liu S, Figueroa ME, Kulalert W, Eminli S, Tan KY et al. Cell type of origin influences the molecular and functional properties of mouse induced pluripotent stem cells. Nat Biotechnol 2010; 28: 848-855.

28. Doi A, Park IH, Wen B, Murakami P, Aryee MJ, Irizarry R et al. Differential methylation of tissue- and cancer-specific $\mathrm{CpG}$ island shores distinguishes human induced pluripotent stem cells, embryonic stem cells and fibroblasts. Nat Genet 2009; 41: 1350-1353.

29. Lister R, Pelizzola M, Kida YS, Hawkins RD, Nery JR, Hon G et al. Hotspots of aberrant epigenomic reprogramming in human induced pluripotent stem cells. Nature 2011; 471 : $68-73$

30. Ohi Y, Qin H, Hong C, Blouin L, Polo JM, Guo T et al. Incomplete DNA methylation underlies a transcriptional memory of somatic cells in human iPS cells. Nat Cell Biol 2011; 13: $541-549$

31. Bar-Nur O, Russ HA, Efrat S, Benvenisty N. Epigenetic memory and preferential lineagespecific differentiation in induced pluripotent stem cells derived from human pancreatic islet beta cells. Cell Stem Cell 2011; 9: 17-23.

32. Ferber S, Halkin A, Cohen H, Ber I, Einav Y, Goldberg I et al. Pancreatic and duodenal homeobox gene 1 induces expression of insulin genes in liver and ameliorates streptozotocin-induced hyperglycemia. Nat Med 2000; 6: 568-572.

33. Kaneto H, Matsuoka TA, Nakatani Y, Miyatsuka T, Matsuhisa M, Hori M et al. A crucial role of MafA as a novel therapeutic target for diabetes. J Biol Chem 2005; 280: 15047-15052.

34. Kaneto H, Nakatani Y, Miyatsuka T, Matsuoka TA, Matsuhisa M, Hori M et al. PDX-1/VP16 fusion protein, together with NeuroD or Ngn3, markedly induces insulin gene transcription and ameliorates glucose tolerance. Diabetes 2005; 54: 1009-1022.

35. Zhou Q, Brown J, Kanarek A, Rajagopa,I J, Melton DA. In vivo reprogramming of adult pancreatic exocrine cells to beta-cells. Nature 2008; 455: 627-632.

36. Saitoh I, Sato M, Iwase Y, Inada E, Nomura T, Akasaka E et al. Generation of mouse STO feeder cell lines that confer resistance to several types of selective drugs. Cell Med 2012; 3 : 97-102.

37. Noguchi $\mathrm{H}$, Kaneto $\mathrm{H}$, Weir GC, Bonner-Weir S. PDX-1 protein containing its own antennapedia-like protein transduction domain can transduce pancreatic duct and islet cells. Diabetes 2003; 52: 1732-1737. 